\title{
EDITORIAL
}

\section{Contribution of Bangladesh Diabetic Samity (BADAS) to Health Care Management}

(Birdem Med J 2012; 2(1): 1-2)

Founded in 1956 through the initiative of late National professor (Dr.) M Ibrahim, Diabetic Association of Bangladesh- (previously DAB and now BADAS) is the largest health care chain in Bangladesh after the public sector. It has grown into a nationwide organization, consisting of around 80 health care and educational facilities spread all over the country.

BADAS has pioneered technologies and services in health care eg it was the first in country to introduce radioimmunoassay and CT scan. Laparoscopic surgery and liver transplant were first carried out successfully in BIRDEM. BADAS has led the way in introducing distance learning programme for teaching diabetes.

Health care services and Manpower development:

1. BADAS and affiliated branches: BADAS has 61 affiliated and subaffilited branches which provide services to diabetic patients throughout the country, numbering over 1600000 (16 lakh), in addition, it provides a vast number of non-diabetic population with diagnostic and therapeutic services.

2. BIRDEM: The Institute has a 600-bed modern multidisciplinary hospital. It has at the moment about 500000 registered diabetic patients, around 3000 patients attend OPD in two shifts; morning and evening.

BIRDEM Academy runs 16 postgraduate courses in various disciplines of medical science. It also conducts research as a result of which it has designated WHO Collaborating Centre for Research on Diabetes and its complication.

3. Health Care Development Project(HCDP)-This is a large scale project for general health care delivery (the Health Care Development Project, HCDP) supported by the Govt of Bangladesh, Dutch Govt and a Consortium of local Banks. Through this project, a network of 20 hospitals and health centers is under the process of implementation in and around Dhaka, as well as in northern parts of Bangladesh upto the Upazilla level. Bangladesh Institute of Health Sciences (BIHS) is the Apex Institute of HCDP which has its associated hospital named as BIHS Hospital. The objective of BIHS is to create a Model Educational Institute encompassing all disciplines of biomedical and health sciences. Presently 5 major Divisions have been planned namely a) Division of Basic Sciences, b) Division of Clinical Sciences, c) Division of Public Health, d)Division of Allied Health Sciences, and e) Division of Nursing. BIHS is run by a Governing Body formed under the rules and regulations of the University of Dhaka.

Bangladesh institute of health science hospital (BIHS) is located in Mirpur, Dhaka. This 250 bed hospital (upgradable to 500 bed) is linked to regional hospital (RH) at Sirajganj, which has 200 beds but upgradable to 300 beds. Threre are four subregional hospitals (SRH) which have 30-75 bed hospitals, and all of them expandable to 100 beds. These are situated in Pabna, Bogra, Dinajpur and Thakurgaon. Each is linked with peripheral health care centre (PHC) with outpatient and diagnostic services. BIHS hospital is linked with ten urban health care centre (UHC) in and around Dhaka city with outpatient and diagnostic facilities. The UHCs are situated in Savar, Bashabo, Jurain, Rampura, Keraniganj, Tongi, Motijheel and Dhanmondi.

4. National Healthcare Network(NHN):The National Healthcare Network, NHN (former NDN), was established in June 1996 as a new project of the BADAS with the primary objective of providing quality diagnostic services throughout the country at a reasonable cost . Subsequently, health-care component was incorporated into it to make it cost 
effective and more comprehensive. Now NHN with its 05 hospitals and 11 Centers provide medicare services to doorsteps of people.

5. Ibrahim Cardiac Hospital and Research Institute (ICHRI): Ibrahim Cardiac Hospital and Research Institute has been established as a not-for profit organization to prevent and treat cardiac patients, to create awareness and to develop skilled manpower. It has already established itself as a highly reputed cardiac institute in the country with a team of dedicated doctors, nurses, technicians and efficient support service management team. It has a 150 bed hospital with facilities for invasive and noninvasive cardiology. Cardiac surgery, Thoracic surgery and Vascular surgery, Cardiac Rehabilitation and Radiology including Volumetric CT Angiogram.

6. Ibrahim Medical college (IMC): Ibrahim Medical College, was established in the year 2002. It offers 5-year MBBS course and admits 100 students yearly. It has an Academic faculty comprising of 194 full-time members.

7. Rehabilitation and Vocational Training Centre (RVTC):

The main objective of Rehabilitation and Vocational Training Centre is to train poor young diabetic patients in different trades to help them to get employment. This helps them to lead a meaningful, respectful life by generating their own means and resources.

\section{Generating Human Resources in Health:}

BADAS has numerous institutes and projects which are engaged in developing health related manpower:

\section{Undergraduate and postgraduate courses:}

In addition to undergraduate course in medicine run by Ibrahim Medical College in Dhaka, Faridpur Diabetic Samity Medical college, Sirajganj, 16 postgraduate courses are offered by BIRDEM, MPH and MPhil, and BSc in laboratory Technology by BIHS, Faridpur Diabetes Samity also offers Nursing Diploma.

BADAS also runs specialized courses in Diabetology through its Distance |Learning Programme. It also recently started Diabetes Educator Programme

Distance Learning Programme(DLP): is project of the Diabetic Association of Bangladesh to run distance learning course with view to develop manpower in the field of diabetes throughout the country. So far it has also trained 4000 doctors, the course was introduced in collaboration with the Open University, UK, in 2004.

Accredited Physicians: BADAS has undertaken an initiative through DLP to train General Practitioners (G.P) all over the country, who in turn may then join the network of BADAS as its accredited physicians.

Please visit our website: www.dab-bd.org 